\title{
A ATUAÇÃo do PROFISSIONAL CONTÁBIL NA GESTÃo DOS PEQUENOS NEGÓCIOS
}

\author{
Cleanecir de Sousa Silva ${ }^{1}$ \\ Italo Campelo Conceição ${ }^{2}$ \\ Antonia Francisca da Silva Saraiva ${ }^{3}$ \\ Walter Saraiva Lopes ${ }^{4}$
}

Resumo: As micro e pequenas empresas (MPEs) são responsáveis pelo crescimento socioeconômico do Brasil. A contabilidade é uma ferramenta de apoio gerencial, mas é necessário que contadores e empreendedores desenvolvam a contabilidade gerencial para auxiliar nas decisões e garantir a sobrevivência do empreendimento no mercado. O objetivo deste artigo é demonstrar a importância da contabilidade gerencial para a sobrevivência das MPEs e como o contador pode auxiliar fornecendo informações. A metodologia deste artigo é uma revisão bibliográfica, embasada em livros, artigos, sites e outras fontes de pesquisas com ênfase nos assuntos pertinentes a MPEs, contabilidade e contador. Nas análises de resultados, conclui-se que os profissionais contábeis podem atuar como auxiliares na gestão dos pequenos negócios como fornecedores de informações que possibilitem aos proprietários segurança nas tomadas de decisões e possa garantir a sobrevivência do empreendimento. Conclui-se que a contabilidade contribui de forma significativa para o desenvolvimento das MPEs e pode garantir a permanência delas no mercado, desde que seja utilizada como ferramenta de gestão.

Palavras-chave: Gestão; Micro e Pequena Empresa; Gestão Empresarial; Contabilidade; Contabilidade Gerencial.

\footnotetext{
1 Ciências Contábeis/ Universidade Federal do Maranhão, Brasil. E-mail: cleanecirsilva@gmail.com.

2 Ciências Contábeis/ Universidade Federal do Maranhão, Brasil. E-mail: dcampelo84@hotmail.com.

${ }^{3}$ Administração de Recursos Humano/Universidade Nove de Julho, Brasil. E-mail: antonyafc@hotmail.com.

${ }^{4}$ Ciências Contábeis/ Universidade Federal do Maranhão, Brasil. E-mail: w.saraiva@yahoo.com.br.
} 